\title{
The Effectiveness of Play Therapy on Reduction of the Symptoms of Attention Deficit Hyperactivity Disorder (ADHD) in Children
}

\author{
Maryam Zakershoshtari ${ }^{1} \&$ Zahra Dasht Bozorgi ${ }^{1}$ \\ ${ }^{1}$ Department of Psychology, Ahvaz Branch, Islamic Azad University, Ahvaz, Iran \\ Correspondence: Zahra Dasht Bozorgi, Department of Psychology, Ahvaz Branch, Islamic Azad University, \\ Ahvaz, Postal Code 61349-37333, Iran. Tel: 98-61-3334-8420. E-mail: zahradb2000@yahoo.com
}

Received: February 5, 2016

Accepted: April 13, 2016 Online Published: May 20, 2016

doi:10.5539/ass.v12n6p188

URL: http://dx.doi.org/10.5539/ass.v12n6p188

\begin{abstract}
This study aimed to investigate the effectiveness of play therapy on reduction of the symptoms of attention defect hyperactivity disorder (ADHD) in children of Ahvaz, Iran. To this end, 20 children with ADHA were selected using the available sampling method using the quasi-experimental design with pretest and posttest and were randomly divided into two groups. Both groups were evaluated using the Conners' scale as the pretest and posttest and the treatment group received play therapy for eight sessions. For data analysis, factorial ANCOVA was used. The results showed that there is a significant difference between the mean scores of pre-test and post-test in the two groups. Follow-up study also showed the lasting effect of the independent variable.
\end{abstract}

Keywords: play therapy, attention deficit, hyperactivity

\section{Introduction}

Attention deficit hyperactivity disorder (ADHD) is one of the most common problems of the children that cause parents refer to the psychiatrists and consultants. It substantially influences on the lives of thousands of children and their families, with symptoms of improper development of hyperactivity, inattention and impulsivity (Biederman \& Faraone, 2011). ADHD is more likely to be diagnosed in boys than in girls and therefore, the boys are more referred to the consultancy centers. ADHD is 3-8\% prevalent in the children (Jonsdottir et al., 2013). Children with symptoms of hyperactivity and inattention are threatened by a variety of problems, including learning problems, behavioral disorders and the risks associated with other disorders, so early intervention is needed to reduce these problems at home and school. Parents spend much time with their children. Many researchers use the information obtained from the parents for identifying children with ADHD in their studies (Shahim, 2007).

Play is a vital component in children development and since the specific methods of the parents are not usable for their children, child therapists consider play as a useful tool for intervening in the children's behavioral problems such as aggression and incompatibility (Esmaili, 2013). A number of studies have shown that play therapy is the most common and most successful therapeutic approach for the children with behavioral problems and more parents are satisfied with this approach (Ghaderi, 2010). Play therapy is focused on improving the relationship between parent-child, children's inner self, and their potential (Kashani, 2011).

Hatami and Beigian (2013) studied the effectiveness of parent-child play therapy on the 4-6 years old hyperactive children's behavioral problems and attention deficit. The results showed that score of the stereotyped behaviors and communication problems as well as attention deficit of the treatment group was reduced compared to the control group, and parent-child play therapy led to the better social interaction of the treatment group to the control group. Moreover, Navaseri and Ahmad Zadeh (2013) investigated the effectiveness of play therapy on attention deficit and aggression in the hyperactive children. The results showed that after 12 sessions of play therapy protocol, no difference was observed in the post-test of the aggression and attention deficit of the hyperactive children in the treatment and control groups.

Khani (2011) evaluated the effectiveness of the play therapy on behavioral problems in ADHD children of Ahvaz. The results indicated that the treatment group that received the play therapy intervention showed less aggression and irritability compared to the control group, therefore, play therapy was effective in reducing the behavioral problems of the hyperactive children.

Tofan et al. (2014) showed that play therapy leads to the more communication of the parent-child and acceptance 
of the parents by the children. It reduced the emotional problems of the children, too.

In addition, Gelarez et al. (2014) examined the effectiveness of the parent-child relationship-based play therapy in a group of 4- 8 years old children and showed that the parents of the children in the treatment group are able to identify and assess their children's anxiety and show more empathy. Furthermore, Dem (2014) evaluated the effects of group play therapy on the attention deficit and supportive performance of the mothers on the hyperactive children and their families in a sample of 20 children. He showed that play therapy approach causes the difference in the post-test scores of the attention deficit and increase in the supportive performance of the mothers compared to the pretest. Therefore, play therapy was effective in reducing the attention deficit and increase in the supportive performance of the mothers with respect to the hyperactive children's perception of their mothers.

With regard to the effect of the play therapy on the children's behavioral and emotional disorders, this study may be categorized in the above-mentioned literature. On the other hand, it shows the effectiveness of the play therapy on the children with ADHD. The results of this study may be used in the therapeutic programs for the children, too. However, this study aims to investigate the effectiveness of play therapy on reduction of the symptoms of attention defect hyperactivity disorder (ADHD) in children.

\section{Method}

A quasi-experimental design with pretest and posttest with treatment and control groups was used. The statistical population in this study included all children with ADHD and parents who referred to the specialized center in Ahvaz in 2015. The research sample consisted of 20 children with ADHD and their mothers that were selected using the available sampling method and were randomly divided into two groups of 10 people in control and treatment groups.

\subsection{Research Instrument}

In this study, for detecting the ADHD in children, Conners' questionnaire was used. This 26-item questionnaire has total score ranging from 26 to 104. The children who achieve the scores higher than 34, suffer from ADHD. The higher the score is the more children will suffer from this disorder and vice versa (Zahraei, 2014). In a study conducted in Iran by Khushabi et al. (2009, quoted by Zahraei, 2014) on 2667 children (7-12 years-old boys and girls) using Pearson correlation method, correlation of each question with the whole test and the validity of the questionnaire were reported $(\alpha=0.93)$. This shows the high validity of the questionnaire. Moreover, validity of the questionnaire was reported using the Cronbach alpha and split-half, as 0.88 and 0.89 , respectively.

\subsection{Procedure}

Play therapy sessions were as follow based on the Landreth's (2006) pattern of training in 8 sessions of 90 minutes for the treatment group:

- communicating with mothers and encouraging them to talk about their children's behavioral problems and attention deficit in the form of the play;

- Introducing the principles and objectives of the play sessions and listing the necessary toys;

- Training mothers to play at home;

- reporting the results of the first play round at home by mothers and considering the attention quality increase-based play;

- raising the awareness about play communications with children;

- training the plays for increasing the children's self-esteem;

- training the mothers to encourage and admire their children; and

- reviewing and summarizing the sessions, surveys and providing the mothers with the final recommendations.

\section{Findings}

As shown in Table 1, in the pre-test, the mean and SD of the symptoms of ADH for the treatment group was 47.80 and 11.23, respectively and for the control group was 49.84 and 10.26, respectively. Moreover, in the post-test, the mean and SD of the symptoms of ADH for the treatment group was 13.11 and 31.71, respectively and for the control group was 49.20 and 9.13, respectively. Additionally, table 1 shows the mean and SD in the follow-up stage for the treatment group was 8.18 and 31.20, and for the control group was 49.70 and 10.96 , respectively. 
Table 1. The mean and standard deviation of the scores of the variables in the two groups

\begin{tabular}{llllll}
\hline variable & stage & group & $\mathrm{N}$ & $\mathrm{M}$ & $\mathrm{SD}$ \\
\hline & \multirow{2}{*}{ pretest } & treatment & 10 & 47.80 & 11.23 \\
& & control & 10 & 49.84 & 10.26 \\
& \multirow{2}{*}{ pretest } & treatment & 10 & 31.71 & 13.11 \\
& & control & 10 & 49.20 & 9.13 \\
& \multirow{2}{*}{ follow-up } & treatment & 10 & 31.20 & 8.18 \\
& & control & 10 & 49.70 & 10.96
\end{tabular}

Table 2. Test results of Levin test on the hypothesis of the equality of pretest variance of the two groups in research variables

\begin{tabular}{cccccc}
\hline stage & variables & F & DF1 & DF2 & Sig \\
\hline pretest & attention deficit & 1.33 & 1 & 18 & 0.234 \\
\hline
\end{tabular}

As shown in Table 2, zero hypothesis for equality of variances of the two groups in the pretest in reducing the symptoms of ADHD is confirmed. This suggests that in analysis of variance of two groups in posttest, due to the variances homogeneity of the groups in the pretest, the effects of the independent variables (play therapy) plays an important role in the potential difference of the scores of these two groups.

Table 3. Results of data normality (Kolmogorov-Smirnov test)

\begin{tabular}{ccccc}
\hline & \multicolumn{2}{c}{ pretest } & \multicolumn{2}{c}{ posttest } \\
\cline { 2 - 5 } & statistic value & Sig & statistic value & Sig \\
\hline ADHD & 0.86 & 0.50 & 0.13 & 0.73 \\
\hline
\end{tabular}

As shown in Table 3, the results of Kolmogorov - Smirnov shows no significant difference between the study variables. In other words, the results indicate a normal distribution of the data.

Table 4. The results of analysis of covariance to compare the post-test in reducing the symptoms of ADH and controlling the pretest of both groups

\begin{tabular}{lllllll}
\hline dependent variable & SS & DF & MS & F & P & Eta \\
\hline reducing the symptoms of attention deficit & 119.26 & 1 & 119.26 & 19.01 & 0.001 & 0.76 \\
\hline
\end{tabular}

As shown in Table 4, controlling the pre-test leads to the significant difference between the treatment and control groups in terms of reducing attention deficit symptoms $(\mathrm{p}<0.001$ and $\mathrm{F}=26.69)$. In other words, personality regard to the mean of reducing the symptoms of attention deficit of the treatment group (31.70) compared to the mean of the ADH symptoms in the control group (49.20) significantly reduces the symptoms of ADH in the treatment group. With respect to the observed F (9.01) and significant level $(\mathrm{p}<0.023)$, the research hypothesis that states "play therapy reduces the symptoms of ADHD in children is activated shortcomings" is confirmed.

Table 5. Analysis of covariance of the reducing the symptoms ADH of two groups by controlling the pretest in follow-up stage of both groups

\begin{tabular}{cccccc}
\hline variables & SS & DF & MS & F & P \\
\hline reduction of attention deficit & 515.11 & 1 & 515.11 & 10.15 & 0.001 \\
\hline
\end{tabular}

As shown in Table 5, controlling the pre-test of the treatment and control groups in terms of reducing the AD 
symptoms leads to a significant difference. In other words, personality with respect to the mean reduction of the AD symptoms in follow-up stage (one month) compared to the control group, has reduced the symptoms of the $\mathrm{AD}$ in the treatment group.

\section{Discussion and Conclusion}

This study aimed to investigate the effectiveness of play therapy on reduction of the symptoms of attention defect hyperactivity disorder (ADHD) in children of Ahvaz. The results showed that controlling the pre-test leads to the significant difference between the treatment and control group in terms of reducing the symptoms of $\mathrm{AD}$. Moreover, the results showed that play therapy with respect to the mean reduction of the ADH symptoms in follow-up stage (one month) compared to the control group, has reduced the symptoms of the ADH in the treatment group. These results are consistent with those of Hatami \& Beigian (2013) Nezhadi et al. (2010) and Dame (2014). Therefore, it can be concluded that the children's cognitive development occurs before the language development. Playing helps the children to increase their knowledge on the surrounding world and communicate with the environment.

In play therapy, toys are regarded as the vocabularies and play is considered as the children's language. In fact, play therapy for children is similar to the counseling or psychotherapy for adults. The symbolic function of the plays helps the children to express their ideas, because the important experiences are easily expressed by the symbols. Play therapy also helps the children to transfer their anxieties, fantasies, and sins to the objects instead of people. Therefore, in this way, they are protected from their emotions, reactions, or fantasies, since playing helps them to separate themselves from the traumatic experiences or events. A frightening or traumatic event is symbolically played and the results may be changed. Danjer (2003) showed that the play therapy as an effective intervention strategy reduced the anxiety of the children.

Another study was conducted on the effectiveness of play therapy in reducing behavioral problems, increasing the emotional adjustment, improving the concept of self-control in North Texas with a sample of 30 subjects on pre-school children. The results indicated the positive tendencies in the children's behaviors. Agerlie and Parker (2005) argued that play therapy is effective on learning, self-control, responsibility, expressing feelings, respect, acceptance of self and others, improving the social skills, self-esteem, reducing the depression and anxiety.

If the play therapy technique is correctly used, it may be regarded as a preventive and therapeutic approach, too. It helps the children to satisfy their childhood needs with no problem. It is also helpful in training the proper social interactions using the group playing, representative playing or so on. Feeling expression, anxieties and anger without hurting self or others are of other advantages of play therapy approach. Therefore, it is a therapeutic training technique. Moreover, most of the psychologists believe that the most part of the human personality is formed in their childhood and in their families. Playing creates enjoyable experiences for the children and helps the families to understand their children in this period. Play therapy helps students to use strategies and life skills in all real environments and situations. Obviously, all those who are responsible for the students and believe in the compiled and comprehensive training programs should provide such an opportunity for these students.

\section{References}

Agerlie, J., \& Parker, R. (2005). Generativity in the play of young people with Autism. Journal of Autism and developmental Disorders, 25(2), 105-120.

Biederman, J., \& Faraone, S. V. (2011). Attention-deficit hyperactivity disorder. Lancet, 366(9481), 237-248.

Danjer, K. D (2003). Play therapy for children with physical Disabilities. Journal of Rehabilitation, 12(2), 51-54.

Dem, K. (2014). The efficacy of life skills training family therapy on affect family of ADHD children. Bilogical Research for Nursing, 9, 147-160.

Esmaili, B. (2013). The effectiveness of play therapy on the family atmosphere, sympathy, and happiness in aggressive children of Ahvaz (Master's thesis). Islamic Azad University of Ahvaz.

Ghadri, M. (2010). The effectiveness of play therapy on the relationship between alexithymia, attachment, and happiness of the incompatible children (Master's thesis). Islamic Azad University of Tehran.

Glazer, W. H., Zimmerman, J., Landreth, G., \& Norton, D. (2014). Life skills training An intervention for parents of children with chronic illness. International Journal of Play Therapy, 1(3), 45-59.

Hatami, F., \& Beigian, A. (2013). The effectiveness of parent-child play therapy on attention deficit and behavioral problems in 4-6 years old hyperactive children. Child Health Journal, 6(7), 47-57. 
Jonsdottir, S., Bouma, A., \& Sergeant, J. A. (2013). The impact of specific language impairment of working memory with ADHD combined subtype. Ach Clin Neropsychol, 20(4), 443-456.

Kashani, R. (2011). The effectiveness of parent-child play therapy based on emotional intelligence of the children (Master's thesis). Allameh Tabatabai University of Tehran.

Khani, M. (2011). Evaluation of effectiveness of play therapy on behavioral problems in ADHD children of Ahvaz (Master's thesis). Islamic Azad University of Mashhad.

Navaseri, A., \& Ahmad Zadeh, R. (2013). The effectiveness of play therapy on attention deficit and aggression in hyperactive children. Journal of Knowledge and Research in Education Sciences, 12(14), 1-22.

Nezhadi, M. (2010). The effectiveness of play therapy on the severity of aggression and hyperactivity of the hyperactive children. Journal of Kermanshah University of Medical Sciences, 5(15), 32-47.

Shahim, S. (2007). The prevalence of attention deficit hyperactivity disorder in elementary school children. Iranian Journal of Pediatrics, 17(2), 211-216.

Tophen, G. L,. Wampler, K. S., Titus, G., \& Rolling, E. (2014). Life skills training of a Filial Therapy program. International. Journal of play therapy, 20(2), 79-93.

Zahraei, F. (2014). The effectiveness of game therapy on children with attention deficit hyperactivity (Master's thesis). Islamic Azad University of Torbat-e Jam.

\section{Copyrights}

Copyright for this article is retained by the author(s), with first publication rights granted to the journal.

This is an open-access article distributed under the terms and conditions of the Creative Commons Attribution license (http://creativecommons.org/licenses/by/3.0/). 